J.R. Maltby MB FFARCS FRCPC, R.G. Loken MD FRCPC, N.C. Watson MB FRCPC

\section{The laryngeal mask airway: clinical appraisal in 250 patients}

nécessita quelques manipulations chez 61 autres. Elle s'avéra impossible chez deux patients qui avaient une petite bouche et on dut procéder à l' insubation de dix autres à cause soit d'obstructions ou de fuites importantes. Contrairement an masque ordinaire, on n'a pas besoin de tenir le masque laryngé et son insertion se fait sans laryngoscope. De plus, il est impossible de le mettre dans l'cesophage et les patients tolèrent facilement sa présence lors du réveil.

Maintenance of a clear airway during general anaesthesia using a face-mask normally requires support of the lower jaw. Constant attention to the position of the patient's head and of the face-mask occupies the anaesthetist's hands, which makes this technique unpopular for all but the shortest surgical procedures. Pressure injury to nerves and eyes may also occur. ${ }^{1-3}$ Tracheal intubation rarely causes injury although damage to teeth and soft tissues may occur, and postoperative sore throat is common. ${ }^{4}$ Increases in heart rate and blood pressure may cause cardiac ischaemia in patients with cardiac disease, and incorrect placement of the tracheal tube in the oesophagus leads to life-threatening hypoxia.

The laryngeal mask (LM) airway ${ }^{5-7}$ is a new device which is intermediate in design and function between an oropharyngeal airway and a tracheal tube. It is made of medical grade silicone and is designed to withstand repeated autoclaving and multiple use. A $12 \mathrm{~mm}$ ID tubular oropharyngeal airway is fused at its distal end to an oval silicone mask (Figure 1) which lies in the hypopharynx, and the inflatable rim provides an airtight seal around the larynx (Figure 2). Its successful use has been reported in spontaneously breathing patients ${ }^{7-8}$ and in patients in whom tracheal intubation was difficult or impossible. $^{9-11}$ The purpose of this study was to assess the efficacy of the LM airway with semiclosed and basal flow anaesthetic techniques for a wide variety of surgical procedures, including abdominal and other major surgery for which intermittent positive pressure ventilation (IPPV) is indicated.

\section{Methods}

The study protocol was approved by the University of Calgary Conjoint Medical Ethics Committee which con- 


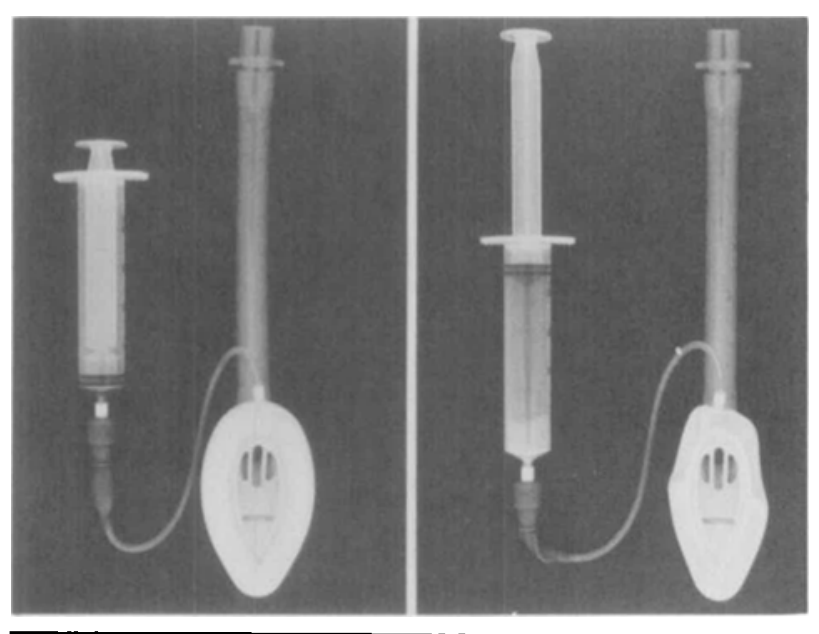

FIGURE I Laryngeal mask airway. Left: deflated for insertion.

Right: cuff inflated.

sidered that special consent for use of the LM airway was not required. Three specialist anaesthetists, none of whom had previously used the LM airway, administered general anaesthesia using this device to 250 patients. The patients' sex, age, weight, dentition, anticipated ease of intubation, and type of surgery were recorded. Obstetrical patients, patients suspected of having a full stomach or who were scheduled for oesophageal or gastric surgery, and those who were to be in the prone position for more than one hour were excluded.

Each investigator selected his usual premedication and anaesthetic technique for the proposed surgical procedure. The LM airway was passed under light inhalational anaesthesia; initially succinylcholine was used by one of the investigators to facilitate insertion but, as experience increased neuromuscular blocking agents were used only in procedures for which muscle relaxation would be required to provide good operating conditions. Following induction of anaesthesia the anaesthetist positioned the patient's head as if a laryngoscopy were to be performed (Figure 3). A deflated LM airway, lubricated with lidocaine two per cent gel, was inserted into the mouth and advanced blindly over the tongue into the pharynx until resistance was felt. The rim was immediately inflated with air and positive pressure was applied to the reservoir bag in order to observe chest movement, to listen for leaks and to auscultate the lung fields, and to observe the end-tidal $\mathrm{CO}_{2}$ monitor and inspiratory pressure. Efficacy was graded as perfect (easy inflation of the lungs with no audible leak); satisfactory (easy inflation, small leak); or unsatisfactory (obstructed ventilation, large leak, or both). When direct passage of the LM airway over the tongue was difficult, a twisting forward movement was used to pass it round the tongue and into the pharynx. If a clear

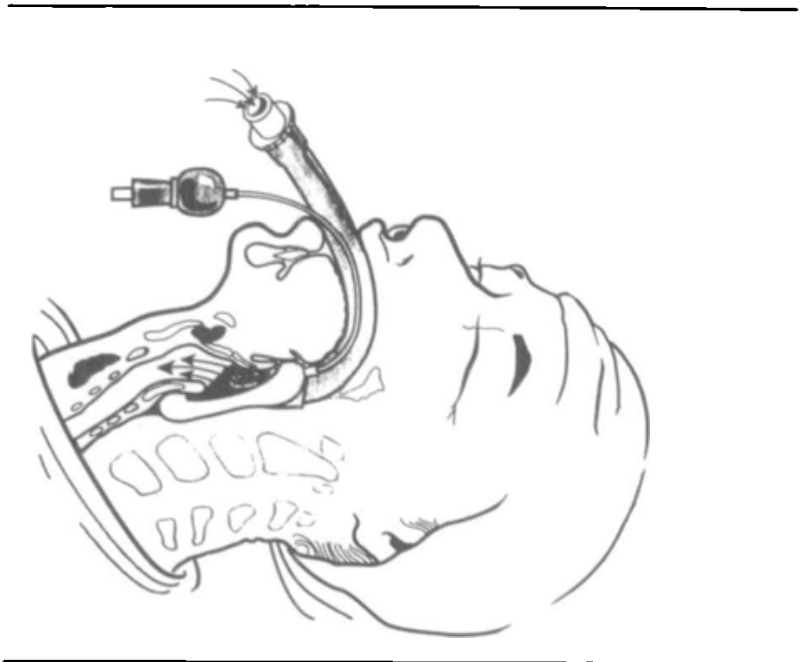

FIGURE 2 Laryngeal mask airway in position with cuff inflated around laryngeal inlet.

airway was not achieved at the first attempt, the device was withdrawn and further attempts were made. A small leak with good chest expansion was considered acceptable for spontaneous respiration. No leak, or a small leak which disappeared within five minutes, were acceptable for intermittent positive pressure ventilation. If placement was unsatisfactory after three attempts laryngoscopy and endotracheal intubation were performed with the aid of a neuromuscular blocking agent. Anaesthesia was maintained with low $\left(3 \mathrm{~L} \cdot \mathrm{min}^{-1}\right)$ or basal $\left(<0.5 \mathrm{~L} \cdot \mathrm{min}^{-1}\right)$ fresh gas flows of nitrous oxide $50-70$ per cent in oxygen, supplemented by opioid, volatile anaesthetic, and neuromuscular blocking agent as required. At the conclusion of surgery the laryngeal mask was left in situ until the patient responded to verbal commands. The cuff was then deflated

TABLE I Demographic and operative details of patients

$\begin{array}{lr}\text { Sex (male : female) } & 89: \\ \text { Age (yr) } & 42 \\ \text { Weight (kg) } & 71 \\ \text { Duration of anaesthesia (min) } & 67 \\ \text { Values are mean } \pm \text { SD (range) } & \\ & \\ \text { Surgical procedure } & \\ \text { Intracranial } & 3 \\ \text { ENT, face } & 21 \\ \text { Arm } & 29 \\ \text { Thorax } & 1 \\ \text { Trunk } & 16 \\ \text { Cholecystectomy } & 10 \\ \text { Lower abdomen } & 65 \\ \text { Cystoscopy, TURP } & 20 \\ \text { D \& C } & 41 \\ \text { Leg } & 44 \\ \text { Total } & 250\end{array}$




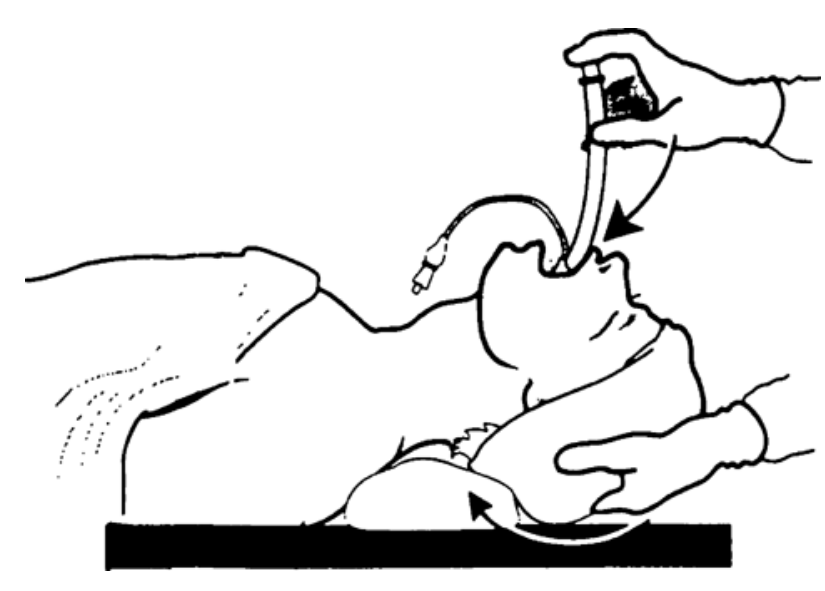

FIGURE 3 Position of the head and neck for insertion of the laryngeal mask airway.

and the patient was asked to remove the device. Patients were visited in the postoperative period to determine the incidence of dryness of the throat, sore throat, and hoarseness.

\section{Results}

The LM airway was used in 250 patients for a wide variety of surgical procedures lasting $10-280 \mathrm{~min}$ in patients aged 14-87 yr who weighed 39-160 kg (Table I). Ease of insertion of the LM airway, efficacy, and the use of spontaneous or controlled ventilation are shown in Table II. Blind insertion was easy in 75 per cent of patients at the first attempt; withdrawal followed by a second or third attempt brought the apparent success rate to 99 per cent. Succinylcholine was given to 36 patients and a nondepolarizing agent to 65 patients prior to insertion. There were only two patients, each of whom had a small mouth, in whom passage over the tongue was impossible. Airway control was unsatisfactory in ten additional patients because of obstruction (five) or a large air leak during IPPV (five). In these cases the LM airway was removed and a tracheal tube was inserted with the aid of a neuromuscular blocking agent.

In the 238 patients who completed the study positioning of the device was perfect in 69 per cent and satisfactory in the remainder. Inspiratory pressure before a leak occurred varied from 10 to $26 \mathrm{~cm} \mathrm{H}_{2} \mathrm{O}$. IPPV was used in 40 per cent of patients; mean inspiratory pressure was $10-16 \mathrm{~cm}$ $\mathrm{H}_{2} \mathrm{O}$ with tidal volume $10 \mathrm{ml} \cdot \mathrm{kg}^{-1}$. The seal around the larynx in the "perfect" patients permitted the use of total fresh gas flows of $0.5 \mathrm{~L} \cdot \mathrm{min}^{-1}$ during maintenance. The LM airway was inserted without difficulty in five patients in whom clinical examination suggested that tracheal intubation might be difficult, including two in whom previous orotracheal intubation was documented as very difficult, in four patients with rheumatoid arthritis affecting the temporomandibular joint or cervical spine, and in 15 with crowns on their incisor teeth.

Insertion of the LM airway at too light a plane of anaesthesia caused coughing and, in three patients, transient laryngospasm when insertion was attempted under thiopentone with or without an opioid. It did not occur when sufficient volatile agent or a muscle relaxant was added before attempted insertion. The LM airway was left in place during emergence until the patient was sufficiently awake to remove it; five patients developed mild laryngeal stridor which did not require active intervention. The device was so well tolerated that some patients tried to talk while it was still in place; vocalization was possible but words could not be distinguished. Postoperative dryness of the throat occurred in 36 per cent of patients, and sore throat in eight per cent. One patient, a heavy smoker, complained of hoarseness.

\section{Discussion}

The principle of the LM airway is similar to that of the pharyngeal bulb gasway which was designed by Dr. Beverly Leech of Regina, Saskatchewan in 1935 (Figure 4). ${ }^{12}$ Before the introduction of muscle relaxants into clinical anaesthesia tracheal intubation was difficult and time-consuming, ${ }^{12,13}$ and few anaesthetists mastered the art. To the distal end of a modified oropharyngeal airway Leech fitted a detachable soft rubber bulb which conformed to the contour of the pharynx and which produced an airtight system without intubation of the patient's trachea. The pharyngeal bulb gasway was especially useful for closed circuit anaesthesia with cyclopropane because it could be inserted at a lighter level of anaesthe-

TABLE II Insertion and efficacy of LM airway

$\begin{array}{lr}\text { LM insertion } & 187 \\ \text { - easy } & 61 \\ \text { - >1 attempt } & 2 \\ \text { - impossible } & \\ \text { Neuromuscular blocker } & 149 \\ \text { - not used } & 101 \\ \text { - used } & \\ \text { LM efficacy } & 164 \\ \text { - perfect } & 74 \\ \text { - satisfactory } & 12 \\ \text { - abandoned } & \\ \text { Ventilation }(n=238) & 143 \\ \text { - spontaneous } & 95 \\ \text { - controlled } & \\ \text { Failures }(n=12) & 2 \\ \text { - failed insertion } & 5 \\ \text { - obstructed airway } & 5 \\ \text { - large leak } & \end{array}$




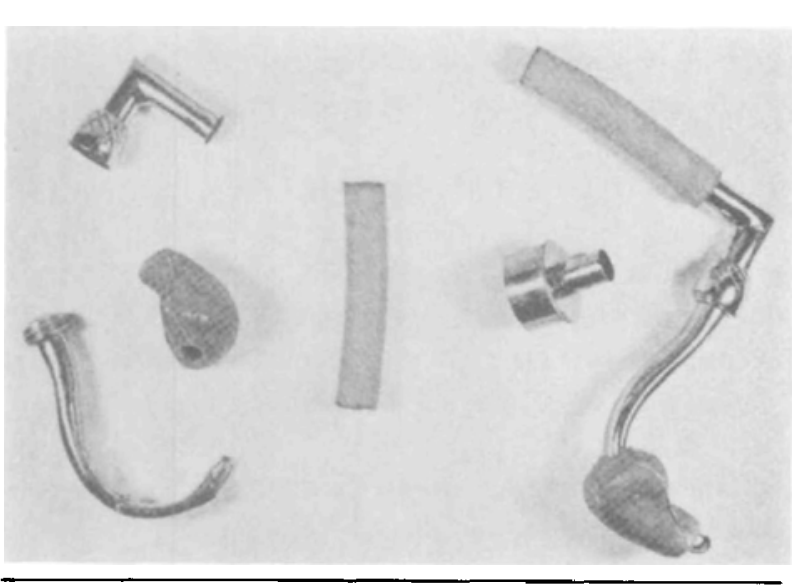

FIGURE 4 Component parts of Leech's pharyngeal bulb gasway with complete apparatus at right.

sia than that required for tracheal intubation, and provided an airtight circuit before cuffed tracheal tubes were commercially available. With the introduction of neuromuscular blocking agents and the manufacture of cuffed tracheal tubes its value decreased and it now exists only in museums.

In the present study the LM airway offered advantages over a face-mask with or without an oropharyngeal airway. A clear airway was maintained without manipulation of the position of the patient's head and mandibular support was not required, even during long cases. The anaesthetist's hands were thus free for record keeping and' other tasks. An airtight circuit was easy to achieve, even in edentulous patients, whereas with a face-mask this may be difficult and persistent attempts to do so may cause pressure injury to the eyes or to various nerves. ${ }^{1-3}$ During transfer to the recovery room the clear airway was again maintained without mandibular support, allowing the anaesthetist to use both hands to guide the patient's trolley or bed. The LM airway was left in place until the patient was sufficiently awake to remove it when asked to do so.

The LM airway also offered advantages over tracheal intubation. Because its large size, and the resistance which is felt by the anaesthetist when it reaches the hypopharynx, the possibility of oesophageal or bronchial intubation is eliminated. The hypopharynx, which is adapted to passage of food and liquids, is less sensitive to a foreign body than the vocal cords and trachea which have powerful protective reflexes. The latter structures remain untouched by the LM airway which can therefore be inserted at a light level of anaesthesia, with or without neuromuscular blockade. Insertion of the LM airway was achieved without difficulty in patients in whom preoperative assessment ${ }^{14}$ suggested that laryngoscopy and tracheal intubation would be difficult. This confirms the experience of others ${ }^{9-11}$ and thus the device is a valuable addition to the anaesthetist's equipment. Insertion under topical anaesthesia was not attempted in patients during the study, although it was achieved on three occasions by one of the investigators on himself. Its use by emergency room physicians and by paramedics appears attractive because of its ease of insertion. However, although insertion is usually easy, confirmation of correct placement of the LM airway is just as essential as it is with tracheal intubation. Partial or complete respiratory obstruction occurred in seven of 250 patients in our study, even though passage over the tongue had been easy in five of them, and immediate withdrawal of the LM airway was necessary, followed by tracheal intubation.

Although the LM airway may make an important contribution to airway management its use is not applicable to every type of surgery. During an open lung biopsy ventilation was adequate, but reinflation of the collapsed portion of lung was not possible because of a leak around the LM airway cuff at higher inspiratory pressures and the LM airway was replaced by a tracheal tube. A similar problem may occur in patients with severe obstructive airway disease who require high inflation pressures. It was also found to be unsatisfactory for palatal surgery because pressure from the Boyle-Davis gag caused kinking of the tubular portion over the lower lip. We agree with the manufacturer's recommendation that the LM airway should not be used in patients who may have a full stomach because it may not protect the airway from aspiration of foreign material. The only circumstance which might justify overruling this warning would be if, after induction of anaesthesia, intubation was impossible; there is one report of its successful use for emergency Caesarean section in this situation. ${ }^{11}$

Each LM airway costs approximately $\$ 80$ and is designed for multiple use. During this study none of the ten samples showed any deteriotation although some were autoclaved more than forty times. A disposable polyvinylchloride tracheal tube costs approximately $\$ 4.00$ so that cost should not be a major consideration in use of the device. Our experience suggests that the LM airway will find an important role in anaesthetic practice.

\section{Acknowledgements}

The authors thank intavent Ltd, 3-5 High Street, Theale, Reading RG7 5AH, England who supplied the laryngeal mask airways for clinical assessment, and for their permission to publish Figures 2 and 3 . Figure 4 is reprinted with permission from the International Anesthesia Research Society from: Leech $B C$. The pharyngeal bulb gasway: a new aid in cyclopropane anesthesia. Anesthesia and Analgesia 1937; 16: 22-25. 


\section{References}

I Lyew MA. Mechanical airway maintenance. Can J Anaesth 1988; 35: 670-1.

2 Glauber DT. Facial paralysis after general anaesthesia. Anesthesiology 1986; 65: 516-7.

3 Munn KA, Williams RT, Shafto $C M$. Transient unilateral blindness following general anacsthesia. Can Anaesth Soc J 1978; 25: 433-5.

4 Atkinson RS, Rushman GB, Lee JA. A Synopsis of Anaesthesia. Bristol: Wright 1982: 236-7.

5 Brain AlJ. The laryngeal mask - a new concept in airway management. Br J Anaesth 1983; 55: 801-4.

6 Brain AlJ, McGHee TD, McAteer EJ, Thomas A, AbuSaad MAW, Bushman JA. The laryngeal mask airway. Development and preliminary trials of a new type of airway. Anaesthesia 1985; 40: 356-61.

7 Broderick $P M$, Webster NR, Nunn JF. The laryngeal mask airway. A study of 100 patients during spontancous breathing. Anaesthesia 1989; 44: 238-41.

8 Alexander $C A$, Leach $A B$. Thompson $A R$, Lister $J B$. Use your Brain! Anaesthesia 1988; 43: 893-4.

9 Brain AIJ. Three cases of difficult intubation overcome by the laryngeal mask airway. Anaesthesia 1985; 40: 353-5.

10 Smith $B L$. Brain airway in anaesthesia for patients with juvenile chronic arthritis. Anaesthesia 1988; 43: 416.

11 Chadwick IS, Vohra A. Anaesthesia for emergency Caesarean section using the Brain laryngeal airway. Anaesthesia 1989; 44: 261-2.

12 Leech $B C$. The pharyngeal bulb gasway: a new aid in cyclopropane anesthesia. Anesth Analg 1937; 16: 22-5.

13 Gillespie NA. Endotracheal Anaesthesia. University of Wisconsin Press 1941: 31-3.

14 Atkinson RS, Rushman GB, Lee JA. A Synopsis of Anaesthesia, 10th Ed., Bristol: IOP Publishing Ltd: 1987; 212-3. 